\title{
Treatment of child anxiety. an exploratory study of the role of maternal anxiety and behaviours in treatment outcome
}

Article

Accepted Version

Creswell, C., Jilletts, L., Murray, L., Singhal, M. and Cooper, P. (2008) Treatment of child anxiety. an exploratory study of the role of maternal anxiety and behaviours in treatment outcome. Clinical Psychology \& Psychotherapy, 15 (1). pp. 38-44. ISSN 1063-3995 doi: https://doi.org/10.1002/cpp.559 Available at https://centaur.reading.ac.uk/14101/

It is advisable to refer to the publisher's version if you intend to cite from the work. See Guidance on citing.

To link to this article DOI: http://dx.doi.org/10.1002/cpp.559

Publisher: Wiley

All outputs in CentAUR are protected by Intellectual Property Rights law, including copyright law. Copyright and IPR is retained by the creators or other copyright holders. Terms and conditions for use of this material are defined in the End User Agreement.

www.reading.ac.uk/centaur 
Central Archive at the University of Reading

Reading's research outputs online 
Treatment of child anxiety: An exploratory study of the role of maternal anxiety and behaviours in treatment outcome

Article

Accepted version

Creswell, C., Willets, Lucy., Murray, L., Singhai, M., \& Cooper, P. (2008). Treatment of child anxiety: an exploratory study of the role of maternal anxiety and behaviours in treatment outcome. Clinical Psychology and Psychotherapy, 15(1), pp. 38-44. doi: 10.1002/cpp.559

Publisher statement: The definitive version is available at onlinelibrary.wiley.com 
CLINICAL PSYCHOLOGY AND PSYCHOTHERAPY: AN INTERNATIONAL JOURNAL OF THEORY AND PRACTICE

Treatment of child anxiety: An exploratory study of the role of maternal anxiety and behaviours in treatment outcome

Cathy Creswell, Lucy Willetts, Lynne Murray, Meghna Singhal \& Peter Cooper

School of Psychology, University of Reading

Short title: Maternal anxiety and behaviours in child anxiety treatment outcome Author for correspondence:

Cathy Creswell

School of Psychology

University of Reading

Whiteknights

Reading

RG6 6AL

U.K.

Tel: 01183785408

Fax: 01183786665

Email: c.creswell@ reading.ac.uk 
Treatment of child anxiety: An exploratory study of the role of maternal anxiety and behaviours in treatment outcome

\begin{abstract}
Anxiety disorders are common amongst parents of anxious children and have been found to impede child treatment outcomes, yet it is unclear whether it is parental anxiety that needs to be targetted in therapy or associated parental behaviours. 22 children (6-12 years) with a current anxiety disorder and their mothers received cognitive-behavioural treatment (CBT) for child anxiety. In addition of the 12 mothers who met criteria for a current anxiety disorder, six received CBT for their own disorder. Assessments were made of the mother-child interaction. The main findings were: (i) children did less well from treatment where their mothers had a current anxiety disorder, (ii) treatment of maternal anxiety disorder did not improve child treatment outcome, and (iii) maternal over-involvement and expression of fear was associated with child treatment outcome. The results suggest that, in the context of maternal anxiety disorder, child treatment outcome may be improved by specifically targeting parenting behaviours.
\end{abstract}

Words $=147$ 
Treatment of child anxiety: An exploratory study of the role of maternal anxiety and behaviours in treatment outcome

It is well established that there is an increased rate of anxiety amongst the parents of anxious children (Last et al., 1987; 1991). A recent bottom-up family history study revealed a particularly high rate of anxiety disorders amongst the mothers of anxious children: two-thirds of the mothers of a sample of children presenting for treatment of an anxiety disorder themselves had a current anxiety disorder (Cooper et al., 2006). Furthermore, maternal anxiety has been found to predict child outcome following treatment for anxiety (Cobham et al., 1998; Cooper et al, 2007; Crawford \& Manassis, 2001; Southam-Gerow, Kendall \& Weersing, 2001; Windheuser, 1977). For example, Cobham and colleagues (1998) reported that where at least one parent was rated as highly anxious, only $38.9 \%$ of anxious children were diagnosis-free following treatment, compared to a recovery rate of $82.4 \%$ where neither parent was rated as highly anxious. Cobham et al (1998) also reported that when four sessions of 'Parent Anxiety Management' (PAM) were added to the CBT treatment package for children who had a highly anxious parent, the proportion of children who were diagnosis-free following treatment increased to $76.5 \%$.

Although the conclusion to be drawn from these studies appears clear, recent research findings have not always confirmed the earlier work. For example, Wood et al. (2006) did not find an association between parental anxiety and child treatment outcome; and, although Bodden et al. (submitted) did find that when one or both parents had an anxiety disorder, favourable child treatment outcome was substantially reduced, they did not find 
that Family-CBT conferred any therapeutic advantage where parents suffered from an anxiety disorder.

One likely explanation for the current uncertainty is the nature of the family treatment delivered. There are two ways in which parental anxiety could impede child response to treatment, and interventions could target one or both (or neither) of these: (i) by virtue of an association between parental anxiety and anxiogenic parenting styles; and (ii) by virtue of the particular difficulties anxious parents experience in supporting their child's treatment.

Certainly there is evidence that parental anxiety is associated with patterns of parenting which themselves promote child anxiety (McLeod, Wood \& Weisz, 2007; Murray et al., 2007a; Wood et al., 2003). Two patterns of parenting that have been strongly implicated in the intergenerational transmission of anxiety are modelling of fearful and/or avoidance responses (e.g. De Rosnay et al., 2006; Gerull \& Rapee, 2004; Murray et al., 2007b) and intrusive or overcontrolling parenting (e.g. Wood et al., 2003). The association between these variables and treatment outcome has not been investigated; however, it seems likely that an anxious mother's expressed fear and avoidance of feared stimuli could work against a treatment aimed at promoting her child's approach to feared stimuli; and, similarly, an anxious mother's overcontrolling parenting style could militate against a treatment aimed at promoting child autonomy. It is difficult to interpret the findings of previous studies in light of this analysis because the critical design and data analytic issues were not addressed. For example, in the study by Cobham et al (1998), the Parent Anxiety Management treatment was effective in terms of a reduction in child anxiety disorder, but there was no reduction in maternal self-reported trait anxiety. Although it is 
possible that, by alerting parents to the role of parental anxiety in the development and maintenance of child anxiety, parents may have been encouraged to act in a less 'anxiogenic manner' around the child, since parenting variables were not assessed, this can only be a speculation. There are similar problems in interpreting the findings of the study by Wood et al. (2006). They did not address parental anxiety directly, but instead focused on those parental behaviours previously found to be associated with child anxiety (i.e. high levels of parental involvement, low levels of autonomy-granting). The focus on parenting in the report of this study may well have obscured the role of parental anxiety. Finally, while the treatment regime of Bodden et al. (submitted) did include strategies to modify problematic family interactions and promote modelling of courageous behaviour, it is not clear whether parental involvement and autonomy granting were specifically targetted.

In summary, despite some contrary reports, the balance of evidence supports the conclusion that parental anxiety militates against optimal treatment outcomes for child anxiety. Additional interventions may be useful in overcoming this; however, it remains an open question whether it is parental anxiety that needs to be targeted, or specific parenting behaviours that may be exacerbated by parental anxiety. Notably, no studies have evaluated the association between maternal behaviours in interaction with their child and child anxiety treatment outcome. The current study constitutes a preliminary investigation of this. Specifically, it is hypothesized that: (i) where mothers of children with anxiety disorders themselves have a current anxiety disorder, children will do less well from treatment than children of mothers who do not have a current anxiety disorder; (ii) treatment of maternal anxiety disorder will be associated with improved child 
treatment outcomes; and (iii) lower levels of maternal modelling of anxious responses and overinvolvement will be associated with improved child treatment outcome.

\section{Method}

\section{Participants}

The participants were 22 children and their mothers referred to a specialist clinic for the treatment of anxiety disorders. The children were all aged between 6 and 12 years of age; half were male. An interviewer established the presence of a current anxiety disorder in the child using the ADIS for DSM-IV: C/P (Silverman \& Albano, 1996). The primary disorders of the children were separation anxiety disorder (11), social phobia (3), generalized anxiety disorder (3) and specific phobia (5) ${ }^{1} .18$ of the children had at least one other comorbid anxiety disorder. 3 children also had a comorbid mood disorder (major depressive disorder) and 5 had a comorbid externalizing disorder (attention deficit/hyperactivity disorder or oppositional defiant disorder).

A second interviewer administered the SCID (First et al., 1996) to the mother to assess current and past history of anxiety and mood disorder. Diagnoses were established following discussion with an experienced diagnostician (PC). In 12/22 cases the mother fulfilled DSM criteria for a current anxiety disorder diagnosis (generalized anxiety disorder (4), social phobia (4), agoraphobia/panic disorder (4)). Seven mothers had at least one comorbid anxiety disorder and 3 had a current comorbid mood disorder (either major depressive disorder, or dysthymia). 


\section{Treatment of maternal anxiety}

Prior to the delivery of child-focused treatment, six of the mothers who had a current anxiety disorder were randomly allocated to up to eight sessions of individual cognitive-behaviour therapy, delivered by an experienced therapist, based on the models of Clark (e.g., 1989, Panic Disorder; 1996, Social Phobia) and Wells (1997, Generalised Anxiety Disorder). Following treatment, mothers were re-assessed using the SCID. Following this phase of treatment 5/6 mothers were free of their primary anxiety diagnosis, and 4/6 mothers were free of any diagnosis.

\section{Treatment of child anxiety}

All families received individual treatment for child anxiety following cognitivebehavioural principles. Specifically, mothers attended eight sessions, conducted over 6-8 weeks, based on the Cool Kids Programme (Rapee, 2000). These sessions were focussed on helping mothers to help their child overcome his/her anxiety-related difficulties. Techniques used included psycho-education, identifying and monitoring children's anxious thoughts, cognitive restructuring, behavioural principles to promote 'brave' behaviour, graded exposure hierarchies, problem solving, social skills training and relapse prevention. The fourth session was also attended by the child. In this session the child was invited to formulate a graded exposure hierarchy with the mother and therapist, and then to take part in a mother-child interaction task (described below) to observe and record maternal responses to the child ${ }^{2}$.

\footnotetext{
${ }^{1}$ Children with a principal diagnosis of specific phobia were only included if they also had another current anxiety disorder including separation anxiety disorder, social phobia or generalised anxiety disorder.

${ }^{2}$ This task was also used as the basis to test feasibility of a video-feedback session with the mother in the subsequent session. The video-feedback session was adapted from Stein et al. (2006) to be relevant to parents of children of this age group. Specifically, the video-recording was used to help the mother identify and challenge key maternal cognitions and behaviours that may have influenced the child's performance during the task. For example, opportunities were taken to identify any, even brief, examples of the mother holding back and allowing the child to achieve the task independently. At these
} 


\section{Assessment of child anxiety}

Assessments of child anxiety were made before the initiation of treatment and on completion of the child treatment phase (within two weeks of treatment completion).

Children and mothers were interviewed using the Anxiety Disorders Interview

Schedule: Child and Parent versions (Silverman \& Albano, 1996) by assessors blind to whether the mother had a current anxiety disorder and whether the mother received individual treatment. Where the child met diagnostic criteria and received a Clinical Severity Rating of 4 or more, based on child or mother report, diagnosis was assigned. A sample of all the ADIS interviews was coded by two of the authors (CC, LW) and there was at least acceptable inter-rater reliability (diagnosis Kappa= .74; clinician severity rating $\mathrm{ICC}=.66)$.

A continuous measure of child anxiety was also obtained: the Trait version of the State-Trait Anxiety Inventory for Children (Spielberger et al., 1973). A parent-report version was used as the sample included young children and, consistent with previous reports, internal consistency for the current sample was good (Chronbach's alpha pre $=.84 ;$ post $=.92$ ).

\section{Assessment of mother-child interaction}

During the fourth treatment session children and mothers both attended. Each motherchild pair was given a list of topics ('My hobbies', 'My favourite holiday', 'My family', 
'How I feel about school', 'My ideal day') and was read the following instructions ' $I$ would like (child's name) to give a short presentation to the video camera. This presentation can be about any one of the topics on the page in front of you. I would like (child) to speak for 3 to 5 minutes on this topic'. Dyads were informed that their interaction would be recorded through a one-way screen and the video that was recorded would only be seen by staff within the clinic and by the mother in the subsequent session. Following an initial five-minute preparation phase, children were asked to give the speech to a portable video-camera. Mothers were seated next to this camera so the child could access feedback from his/her mother throughout the task. The therapist gave a warning knock after three minutes and then knocked again each minute until the task was over at five minutes. If a Dyad had clearly finished the task after three minutes, but before five minutes, the task was ended. A coding scheme was developed to assess aspects of the parent-child interaction have been found to be associated with child anxiety, specifically (i) over-involvement and (ii) mother's expressions of fearfulness. These behaviours were coded during the episode in which the child delivered the speech. Over-involved behaviours were defined as instances when mothers provided more help than was necessary in order to support the child. Examples included giving directions and/or instructions when a suggestion was likely to have been adequate, and rapidly intervening when the child paused in speech preparation or delivery. The extent of over-involved behaviours was coded on a scale from 1-5 with $1=$ giving excessive help throughout to $5=$ giving no excessive help at all. Mother's expressions of fearfulness were also coded. These ratings were based on the mother's body language and posture and examples included the mother being stiff and tense, fidgety, shaky. This was also scored on a scale from 1-5 where $1=$ 
instances of anxious body language throughout, and $5=$ no instances of anxious body language at all.

Two coders (both psychology graduates, blind to child and maternal diagnoses) received approximately 10 hours of training on the coding scheme (this continued until raters were achieving consensus ratings). Five (25\%) novel tapes were then coded independently. Inter-rater reliability for overinvolvement was ICC $=.60$. Raters agreed exactly on all ratings of mother's expressions of fearfulness for both phases $(\mathrm{ICC}=1.00)$.

\section{Results}

Data were screened following Tabachnich \& Fidell (1996) and all continuous variables conformed with the assumptions of parametric tests, with the exception of the two behavioural scales which tended to be negatively skewed. These ratings were, therefore, dichotomised to provide indices of high and low overinvolvement/ expressions of fear. Table 1 provides the means, standard deviations and range for all variables.

Hypothesis 1: i.e. where mothers of children with anxiety disorders themselves have a current anxiety disorder, children will do less well from treatment than children of mothers who do not have a current anxiety disorder.

$41 \%$ of children were free of their primary anxiety diagnosis following treatment.

Where mothers were diagnosed with a current anxiety disorder at the initial assessment, $25 \%$ of children were free of their primary diagnosis following treatment, 
in comparison to $60 \%$ of children whose mothers did not have a current anxiety disorder. This difference approached statistical significance $\left(\chi^{2}(1)=2.76, p=.09\right)$. Based on the composite Clinician Severity Rating (CSR) for child anxiety disorders, there was a significant difference between post-treatment composite CSRs for children of mothers with and without a current anxiety disorder, controlling for pretreatment composite $\operatorname{CSR}(\mathrm{F}(2,19)=4.57, \mathrm{p}=.02)$ (see Table 1). A similar pattern of results was found based on the questionnaire measure of child anxiety (STAIC). Here a significant association was found between mother anxiety diagnosis and the STAIC $(\mathrm{F}(2,16)=4.48, \mathrm{p}=.04)$, controlling for pre-treatment score on the STAIC (see table 1). The hypothesis was, therefore, broadly confirmed.

Hypothesis 2. i.e. Treatment of maternal anxiety disorder will be associated with improved child treatment outcomes.

Where mothers received treatment of their own anxiety disorder $(n=6)$, one child $(17 \%)$ was free of their primary diagnosis following treatment. This was not significantly different from the two (33\%) children free of an anxiety disorder posttreatment whose mother had an anxiety disorder which was not treated $\left(\chi^{2}(1)=.44\right.$, $\mathrm{p}=.50$ ). Notably, some mothers who were only involved in the child-focussed treatment lost their anxiety disorder diagnosis following this treatment $(n=3 / 6)$. Children's outcomes were not different if mothers recovered from anxiety or retained their anxiety diagnosis. The hypothesis was therefore not supported. 
Hypothesis 3: i.e. Lower levels of maternal modelling of anxious responses and maternal overinvolvement will be associated with improved child treatment outcome, over and above the effect of maternal anxiety disorder.

Maternal anxiety disorder was not significantly related to maternal behaviours (overinvolvement, $\chi^{2}(1)=.20, p=.65$ (50\% 'high' for anxious mothers, $40 \%$ 'high' for non-anxious mothers; fear expression, $\chi^{2}(1)=.27, \mathrm{p}=.61(30 \%$ 'high' for anxious mothers; $20 \%$ 'high' for non-anxious mothers). The proportion of children who were diagnosis free following treatment was not significantly associated with the ratings of maternal behaviour (overinvolvement, $\chi^{2}(1)=.30, p=.58$; fear expression, $\chi^{2}(1)=$ $1.11, \mathrm{p}=.29$ ). Based on the composite Clinician Severity Rating (CSR), however, significant associations were found with both overinvolvement $(\mathrm{F}(2,17)=3.48, \mathrm{p}=$ $.05)$ and fear expression $(\mathrm{F}(2,17)=4.37, \mathrm{p}=.03)$, controlling for pre-treatment composite CSR. Consistent with these findings, maternal expression of fear during the task was associated with post-treatment STAIC, controlling for pre-treatment STAIC $(\mathrm{F}(2,17)=5.13, \mathrm{p}=.03)$. Significant results were not found for overinvolvement and child outcome on the STAIC $(\mathrm{F}(2,17)=2.06, \mathrm{p}=.17)$. The hypothesis therefore received partial support.

\section{Discussion}

This exploratory study offers some interesting suggestions on issues of current uncertainty in the literature on the treatment of child anxiety. Consistent with the findings of Cobham et al (1998), the presence of a current maternal anxiety disorder was associated with impaired child anxiety outcome based on both parent report and clinician ratings; and analyses using more conservative child anxiety diagnostic outcomes approached significance. However, neither treatment of maternal anxiety 
disorder, nor recovery from maternal anxiety, was associated with improved child treatment outcome. This finding must, of course, be viewed with extreme caution, given the small sample size. Although not statistically significant, mothers with a current anxiety disorder displayed a pattern of increased over-involvement and fear expression. Most notably, maternal over-involved behaviours were found to be associated with less favourable clinician's ratings of child treatment outcome and maternal non-verbal expressions of fear were associated with poorer child treatment outcome, both in terms of clinician ratings and parental report.

A number of limitations of this study must be noted. In particular, the small sample size means that the findings cannot be regarded as reliable; and they must be regarded as merely pointing to hypotheses worthy of further investigation. It should also be noted that there was no assessment of change in maternal overinvolvement and fear expression; and we do not know whether the measure of parenting taken related to change or rigidity in parental behaviours in response to treatment.

It was surprising that recovery from maternal anxiety disorder was not associated with improved child outcome. Although the sample was far too small to regard this as a reliable finding, it is interesting to speculate on its possible implications. One compelling interpretation is that improvement in maternal anxiety, without improvement in the critical parenting variables, is not sufficient to alter the course of child treatment response. Certainly, studies from other areas of developmental psychopathology suggest that changes in maternal psychopathology and parenting can be independent (see review by Nylen, Moran, Franklin, \& O'Hara, 2006). Only larger 
scale controlled enquiry can confirm or disconfirm this hypothesis in relation to child anxiety.

Although this was a small preliminary investigation, to our knowledge it represents the first to investigate (i) the association between maternal anxiety disorder and child anxiety treatment outcome, and (ii) the association between parenting behaviours frequently linked to the aetiology of child anxiety and child anxiety treatment outcomes. While only the most tentative conclusions can be drawn, the findings suggest that targeting the parenting behaviours that are associated with maternal anxiety may be necessary to improve the outcome of treatment for anxious children with anxious mothers. This idea merits systematic investigation. 
Table one

Means, standard deviations and range for all variables.

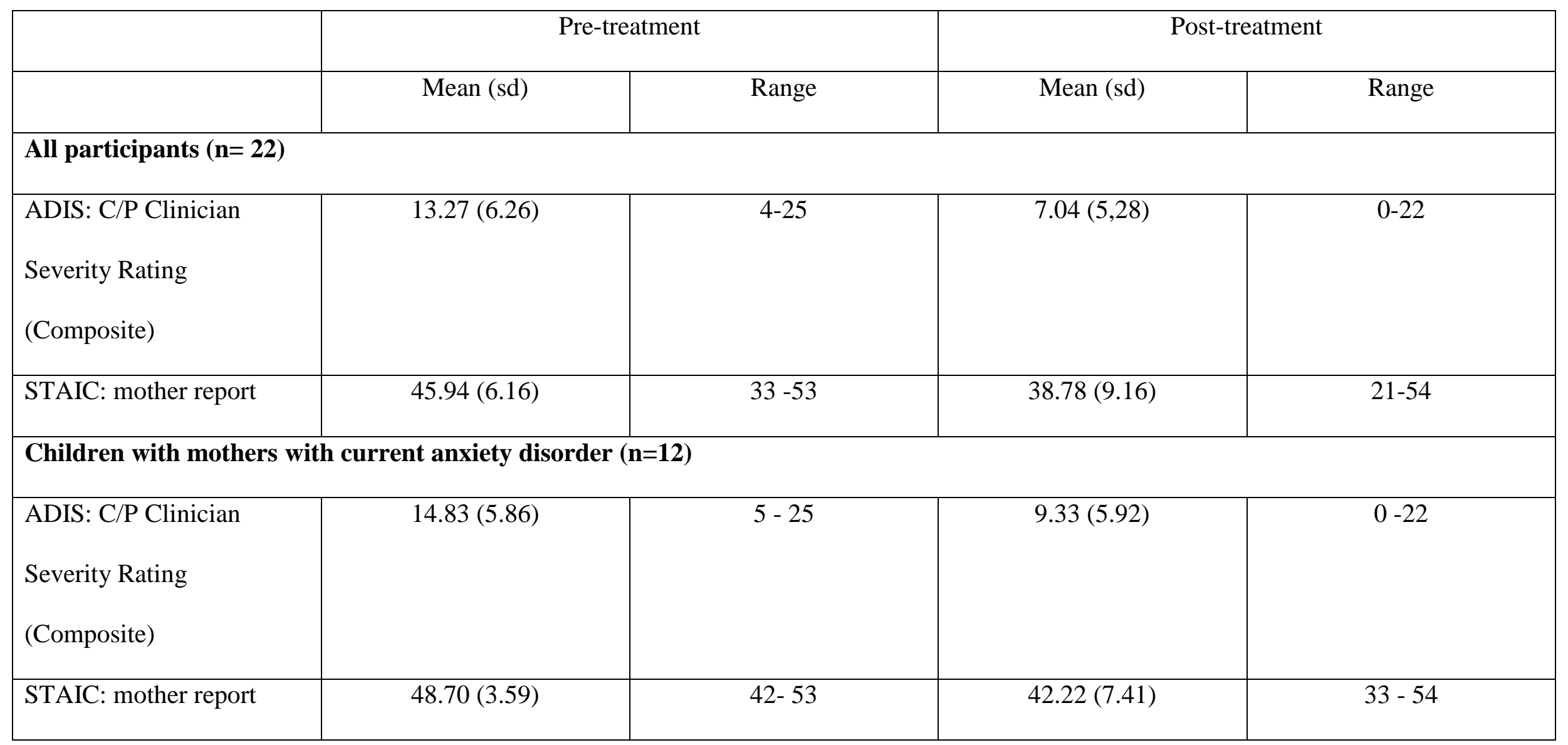




\begin{tabular}{|l|c|c|c|c|}
\hline \multicolumn{2}{|l|}{ Children with mothers with no current anxiety disorder (n=10) } \\
\hline ADIS: C/P Clinician & $11.40(6.52)$ & $4-22$ & $4.30(2.58)$ & \\
Severity Rating & & & & \\
(Composite) & & & $35.33(9.84)$ & $21-54$ \\
\hline STAIC: mother report & $42.50(7.15)$ & $33-50$ & \\
\hline
\end{tabular}




\section{References}

Bodden, D. H. M., Bogels, S. M., Nauta, M. H., de Haan, E., Ringrose, J., Appelboom, C., et al. (submitted). Efficacy of individual versus family cognitive behavioural therapy in clinically anxious youth.

Clark, D.M. (1989). Anxiety states: panic and generalized anxiety. In K. Hawton, P.M. Salkovskis, J. Kirk, \& D.M. Clark (eds). Cognitive therapy for psychiatric problems: A practical guide. Oxford: Oxford University Press. pp 52-96.

Clark, D.M. (1996). Panic disorder and social phobia. In D.M. Clark and C.G. Fairburn (eds). Science and practice of Cognitive Behaviour Therapy. Oxford: Oxford Medical Publications. pp 119-154.

Cobham, V. E., Dadds, M. R., \& Spence, S. H. (1998). The Role of Parental Anxiety in the Treatment of Childhood Anxiety. Journal of Consulting and Clinical Psychology, 66(6), 893-905.

Cooper, P. J., Gallop, C., Willetts, L., \& Creswell, C. (submitted). Treatment response in child anxiety is differentially related to the form of maternal anxiety disorder.

Cooper, P.J., Fearn, V., Willetts, L., Seabrook, H., \& Parkinson, M. (2006). Affective disorders in the parents of anxious children. Journal of Affective Disorders, 93, 205-212.

Crawford, A. M., \& Manassis, K. (2001). Familial Predictors of Treatment Outcome in Childhood Anxiety Disorders. Journal of the American Academy of Child and Adolescent Psychiatry, 40(10), 1182-1189.

de Rosnay, M., Cooper, P. J., Tsigaras, N., \& Murray, L. (2006). Transmission of social anxiety from mother to infant: An experimental study using a social referencing paradigm. Behaviour Research and Therapy, 44(8), 1165-1175. 
First, M.B., Spitzer, R.L., Gibbon, M., \& Williams, J.B.W. (1996). Structured clinical interview for DSM-IV axis I disorders - Research version. Washington: American Psychiatric Press.

Gerull, F. C., \& Rapee, R. M. (2002). Mother knows best: effects of maternal modelling on the acquisition of fear and avoidance behaviour in toddlers. Behaviour Research and Therapy, 40, 279-287.

Last, C. G., Hersen, M., Kazdin, A. E., Francis, G., \& Grubb, H. J. (1987). Psychiatric illness in the mothers of anxious children. American Journal of Psychiatry, 144, $1580-1583$.

Last, C. G., Hersen, M., Kazdin, A. E., Orvaschel, H., \& Perrin, S. (1991). Anxiety disorders in children and their families. Archives of General Psychiatry, 48, 928936.

McLeod, B.D., Wood, J.J., \& Weisz, J.R. (2007). Examining the association between parenting and child anxiety: A meta-analysis. Clinical Psychology Review, 27(2), 155-172.

Murray, L., Cooper, P.J., de Rosnay, M., Pearson, J., \& Sack, C. (2007b). Intergenerational transmission of maternal social anxiety: The role of social referencing processes. Child Development (in revision).

Murray, L., Cooper, P., Creswell, C., Schofield, E., \& Sack, C. (2007). The effects of maternal social phobia on mother-infant interactions and infant social responsiveness. Journal of Child Psychology and Psychiatry, 48, 45-52.

Nylen, K.J., Moran, T.E., Franklin, C.L., O’Hara, M.W. (2006). Maternal depression: A review of relevant treatment approaches for mothers and infants. Infant Mental Health Journal, 27, 327-343. 
Rapee, R. M. (2000). Group treatment of children with anxiety disorders: outcome and predictors of treatment response. Australian Journal of Psychology, 52(3), 125-129.

Silverman, W.K. \& Albano, A.M. (1996). The Anxiety Disorders Interview Schedule for DSM-IV - Child and Parent versions. San Antonio. TX: Psychological corporation.

Southam-Gerow, M. A., Kendall, P. C., \& Weersing, V. R. (2001). Examining outcome variability: Correlates of treatment response in a child and adolescent anxiety clinic. Journal of Clinical Child Psychology, 30(3), 422-436.

Spielberger,C.D. (1973). Manual for State-Trait Anxiety Interview for Children. Palo Alto, CA: Consulting Psychologists Press.

Stein, A., Woolley, H., Senior, R., et al. (2006). Treating disturbances in the relationship between mothers with bulimic eating disorders and their infants: a randomised, controlled trial of video-feedback. American Journal of Psychiatry, 163 (5), 899-906.

Wells, A. (1997). Cognitive therapy of anxiety disorders: A practical guide. West Sussex: Wiley.

Windheuser, H. J. (1977). Anxious mothers as models for coping with anxiety. Behavior Analysis and Modification, 2(1), 39-58.

Wood, J. J., Piacentini, J. C., Southam-Gerow, M., Chu, B. C., \& Sigman, M. (2006). Family Cognitive Behavioral Therapy for Child Anxiety Disorders. Journal of the American Academy of Child \& Adolescent Psychiatry, 45(3), 314-321.

Wood, J., McLeod, B. D., Sigman, M., Hwang, W.C., \& Chu, B. C. (2003). Parenting and childhood anxiety: Theory, empirical findings and future directions. Journal of Child Psychology \& Psychiatry \& Allied Disciplines, 44(1), 134-151. 


\section{Acknowledgements}

The authors would like to thank Liesbeth Teagle, Hannah Seabrook and Kim Freeman for their help with coding and data management. We would also like to thank all the families that took part in this research. 